\title{
Molecular Typing and Identification of Antimicrobial Resistance Markers in Neisseria gonorrhoeae positive Clinical Specimens Collected in a Remote Northern Region of Canada
}

I. MARTIN ${ }^{1}$, S. PETERSON ${ }^{1}$, P. SAWATZKY ${ }^{1}$, M. MATHESON ${ }^{2}$, C. EDDIE ${ }^{2}$, H. HANNAH ${ }^{2}$, A. CORRIVEAU², M. R. MULVEY ${ }^{1}$

${ }^{1}$ National Microbiology Laboratory (NML), Public Health Agency of Canada (PHAC), ${ }^{2}$ Department of Health and Social Services, Government of the Northwest Territories

\section{BACKGROUND}

Reported rates of gonorrhea have increased dramatically in Canada, ${ }^{1}$ with reports suggesting a high burden in remote northern regions; antimicrobial resistance (AMR) to currently recommended antimicrobials have been reported and the primary diagnostic used is nucleic acid amplification testing (NAAT). Molecular assays were used to provide enhanced molecular typing and predicted molecular AMR data on NAAT specimens from a remote northern region in Canada.

\section{METHOD}

Between 2015 and 2017, we evaluated 1,220 (2015, n=335; 2016, n=444; 2017, $\mathrm{n}=441$ ) Neisseria gonorrhoeae positive NAATS (Aptima urine and urogenital swabs) submitted by Northwest Territories for $N$. gonorrhoeae multi-antigen sequence typing (NG-MAST). ${ }^{2}$ Of these, 401 were further analyzed for resistance mutations to cephalosporins (CEPH), ${ }^{3}$ ciprofloxacin (CIP) ${ }^{4}$ and azithromycin (AZI) ${ }^{5}$ by single nucleotide polymorphism (SNP) real-time PCR assays (Table 1).

\begin{tabular}{|c|c|c|}
\hline Antimicrobial & Gene Target & SNP Detected \\
\hline- & porA & Positive control for N. gonorrhoeae \\
\hline \multirow{4}{*}{ CEPH } & ponA & L421P \\
\hline & $m t r R$ & A deletion in promoter \\
\hline & penA & Mosaic penA \\
\hline & porB & Wild type G120, A121 \\
\hline \multirow{2}{*}{ CIP } & gyrA & Wild type S91, D95 \\
\hline & parc & Wild type D86, S87, S88 \\
\hline AZI & $23 \mathrm{~S}$ & Wild type, 2059, 2611 \\
\hline
\end{tabular}

CEPH: Decreased Susceptibility (DS) $=4 / 4$ SNPS (MIC $\geq 0.125 \mathrm{mg} / \mathrm{L}$ ); Intermediate (I) $=3 / 4$ SNPS (MIC $=0.032-0.063 \mathrm{mg} / \mathrm{L}) ;$ Susceptible $(\mathrm{S})=0-2 \mathrm{SNPS}(\mathrm{MIC} \leq 0.016 \mathrm{mg} / \mathrm{L})$ CIP: Resistant (R) $\geq 1 \mathrm{SNP}(\mathrm{MIC} \geq 1 \mathrm{mg} / \mathrm{L}) ; \mathrm{S}=$ All wild type (WT) (MIC $\leq 0.5 \mathrm{mg} / \mathrm{L})$ AZI: $R \geq 1 \mathrm{SNP}$ (MIC $\geq 1 \mathrm{mg} / \mathrm{L}) ; \mathrm{S}=$ All WT (MIC $\leq 0.5 \mathrm{mg} / \mathrm{L}$ )

\section{RESULTS}

Sequence types (ST) were obtained for over $\mathbf{9 0 \%}(1,127 / 1,220)$ of the specimens tested (Table 2).

Out of a total of 53 STs identified from 2015-2017, ST4637 (44.3\%, 499/1,127) and ST10451 (20.6\%, 233/1,127) the most prevalent (Fig. 2).

$70 \%$ of the 401 specimens analyzed for resistance-associated mutations yielded results to predict susceptibility to cephalosporins, ciprofloxacin and azithromycin (Table 3)

Specimens identified as ST4637 were predicted to be susceptible to cephalosporins, ciprofloxacin and azithromycin based on SNP Assay (Fig. 3).

Specimens identified as ST10451 were predicted to have decreased susceptibility to cephalosporins $(87.3 \%, 62 / 71)$ and resistance to ciprofloxacin (100\%, 79/79)(Fig. 3)

\section{CONCLUSIONS}

- The majority of the $N$. gonorrhoeae strains circulating in this region belong to two sequence types; ST4637 and ST10451.

ST10451 emerged in 2016 and was the most prevalent sequence type in 2017; it is associated with predicted cephalosporin decreased susceptibility and ciprofloxacin resistance.

- The enhanced molecular typing and predicted molecular antimicrobial resistance surveillance data will allow public health authorities to better understand the transmission of gonococcal infections and guide public health decision-making in the prevention, treatment and control of gonorrhea in remote regions where cultures are not available.

\section{REFERENCES}

1. Public Health Agency of Canada. 2017. Notifiable Diseases On-Line.

http://diseases.canada.ca/notifiable/charts? $c=y l$ Accessed: 2017/11/14

2. Martin IMC, Ison CA, Aanensen DM, Fenton KA and Spratt BG. 2004. J Infec Dis.

189:1497-1505.

3. Peterson SW, Martin I, Demczuk W, Bharat A, et al. 2015. J Clin Microbiol.53:2042-2048.

4. Peterson SW, Martin I, Demczuk W, Bharat A, et al.. 2015. J Clin Microbiol. 53:3606-3608.

5. Trembizki E, Buckley C, Donavan B, et al. J Antimicrob Chemother. 2015;70:3244-3249.

6. Saitou N. and Nei M. 1987. Mol Biol Evol. 4:406-425.

7. Nei M. and Kumar S. 2000. Mol Evol Phylo. Oxford University Press, New York.

8. Tamura K, Stecher G, Peterson D, Filipski A, and Kumar S. 2013. Mol Biol Evol .30: 2725-

Table 2. Northwest Territories' NAAT Samples Tested

\begin{tabular}{|c|c|c|c|c|c|c|}
\hline \multirow{2}{*}{ Year } & \multirow{2}{*}{$\begin{array}{l}\text { Samples } \\
\text { Received }\end{array}$} & \multirow{2}{*}{ Cases } & \multirow{2}{*}{$\begin{array}{c}\text { Cases } \\
\text { successfully } \\
\text { typed by NG- } \\
\text { MAST }\end{array}$} & \multicolumn{3}{|c|}{$\begin{array}{c}\text { Number of cases with SNP AMF } \\
\text { predictions }\end{array}$} \\
\hline & & & & CEPH & CIP & AZI \\
\hline 2015 & 346 & 335 & 303 & 59 & 46 & 53 \\
\hline 2016 & 454 & 444 & 403 & 138 & 144 & 147 \\
\hline 2017 & 446 & 441 & 421 & 110 & 105 & 107 \\
\hline TOTAL & 1,246 & 1,220 & 1,127 & 307 & 295 & 307 \\
\hline
\end{tabular}

Figure 2. Distribution of NG-MAST of NAAT Samples

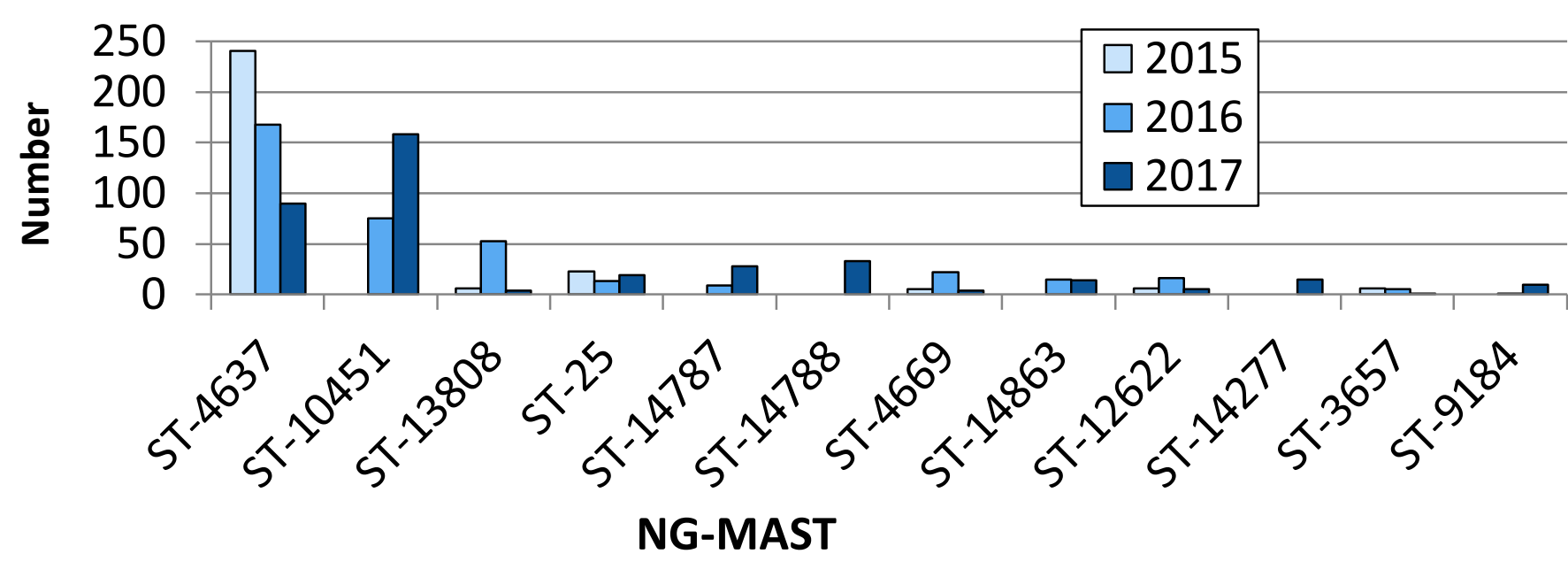

Table 3. SNP Assay Results

\begin{tabular}{|c|c|c|c|c|}
\hline \multirow{2}{*}{$\begin{array}{c}\text { Number } \\
\text { of } \\
\text { Samples }\end{array}$} & \multicolumn{3}{|c|}{$\begin{array}{l}\text { SNP Assay Predicted } \\
\text { Susceptibility }\end{array}$} & \multirow[t]{2}{*}{ NG-MAST Sequence Type } \\
\hline & CEPH & CIP & AZI & \\
\hline 173 & $S$ & $S$ & S & $\begin{array}{c}\text { ST4637 }(n=38), \text { ST14863 }(n=16), \text { ST25 } \\
(n=15), \text { ST13808 }(n=16)^{a}\end{array}$ \\
\hline 12 & S & $\mathrm{R}$ & s & $\operatorname{ST} 15602(n=5)$, ST10451 $(n=4)^{a}$ \\
\hline 22 & 1 & $\mathrm{R}$ & S & $\begin{array}{c}\text { ST10451 }(n=5), \text { ST9184 }(n=6), \text { ST15647 } \\
(n=5)^{a}\end{array}$ \\
\hline 72 & DS & $\mathbf{R}$ & S & ST10451 (n=61), ST14277 $(n=8)^{a}$ \\
\hline
\end{tabular}

aplus other STS

Figure 3. Genetic Relationship ${ }^{6,7,8}$ between NG-MASTs of NAATs $(\mathrm{N}=1,086)^{\mathrm{a}}$

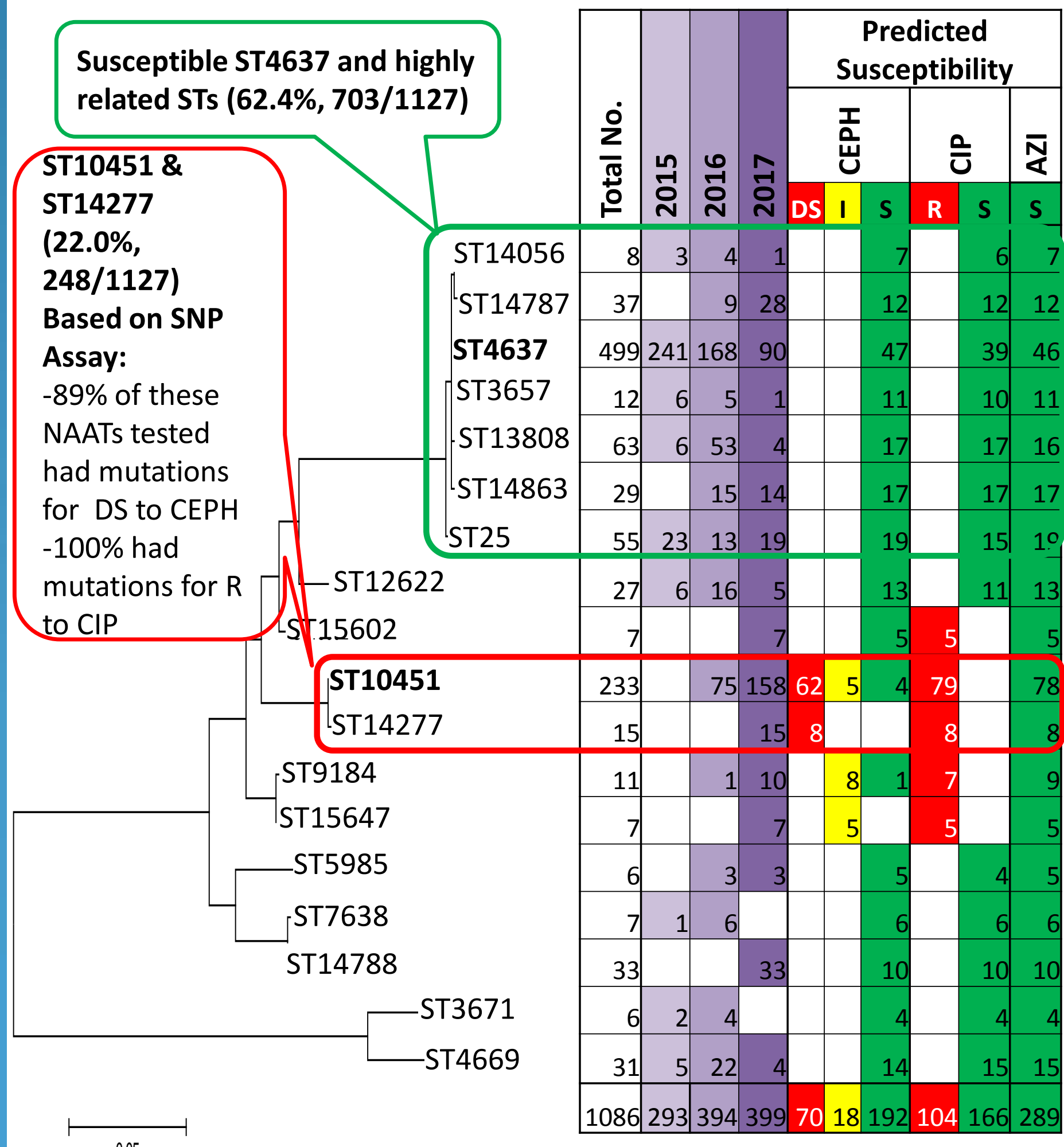

aonly most prevalent STs represented in figure; remaining 40 isolates are distributed among 35 STs with 1 or 2 isolates in each 